\title{
DE IMMIGRATIE VAN HINDOSTANEN EN DE AFSTAND VAN DE GOUDKUST
}

Toen na de afschaffing van de slavernij het te verwachten was, dat na de opheffing van het staatstoezicht het arbeidsvraagstuk in Suriname zeer nijpend zou worden, besloot de Nederlandse Regering stappen te nemen om werkkrachten uit het toenmalige Brits-Indië te werven, daar de Hindostaanse immigranten in de Engelse en Franse koloniën bijzonder goed voldaan hadden. Een moeilijkheid echter was, dat deze gewilde arbeiders de onderdanen van een vreemde mogendheid waren. En daarom werd op 8 september 1870 een tractaat gesloten tussen Nederland en Engeland, dat op 20 januari 1872 werd afgekondigd. ${ }^{1}$ Dit tractaat maakte het mogelijk, dat op 26 februari 1873 het zeilschip 'Lalla $R o o k h$ ' de haven Calcutta kon verlaten, en dat op 5 juni 1873 de eerste groep van 4ro Hindostanen voet aan wal kon zetten in Suriname,* in hetzelfde jaar gevolgd door nog vier groepen van $580,652,477$ en 422 personen.

Over de totstandkoming van dit voor Suriname zo belangrijke tractaat vinden wij zowel in de oudere als in de nieuwere literatuur vermeld, dat Engeland deze concessie aan Nederland deed in ruil voor de afstand van de Nederlandse bezittingen aan de kust van Guinea (Goudkust). Officieel wordt deze mededeling gedaan in het Immigratie-Rapport, ${ }^{2}$ waarop wij jammer genoeg niet de hand konden leggen toen we dit artikel schreven.

Naar dit rapport verwijzend, schrijft DE KLERK ${ }^{3}$ : "Dit recht (n.l. de werving en inscheping in Brits-Indië van arbeiders voor Suriname) zou Nederland verkregen hebben in ruil voor het bezit van onze kolonie aan de kust van Guinea (Goudkust), die inder-

* Opgemerkt dient te worden, dat deze immigranten wel de eerste Hindostanen rechtstreeks uit India waren, doch niet de eerste Hindostanen die naar Suriname kwamen; immers, in 1869 waren er reeds 46 Hindostanen uit Brits-Guyana gearriveerd, in 1870 gevolgd door 24 Hindostanen uit West-Indië. (Vide: Koloniaal Verslag van die jaren). 
daad in diezelfde tijd aan Engeland overging ... De Koloniale Verslagen zwijgen echter over deze conditie."

Duidelijker (en uitgebreider) schrijft KRUIJER 4: "De immigratie van Hindostanen in Suriname was het gevolg van een in I 872 gesloten verdrag tussen Nederland en Groot-Brittannië, waarbij Engeland de Nederlandse bezittingen aan de Goudkust ontving (plantage-arbeiders konden daar niet meer worden gehaald!) en Nederland het recht kreeg om in Brits-Indië arbeidskrachten voor Suriname te werven. Bovendien deed Engeland afstand van zijn aanspraak op Atjeh, waarna de Nederlanders in dit gebied de vrije hand kregen en in 1873 de Sultan van Atjeh de oorlog verklaarden."

Het meest recente voorbeeld van deze zienswijze vonden wij in het artikel van MEIJER ${ }^{5}$ in het standaardwerk over de Nederlandse geschiedenis, waarin staat: "In I87o kwam een tractaat tot stand, waarbij Engeland toestemming tot immigratie verleende, in ruil voor het afstaan van de Goudkust van Afrika. De overeenkomst werd in 1872 afgekondigd en in 1873 kwam het eerste schip met immigranten in Paramaribo aan."

Intussen blijkt deze opvatting niet juist te zijn en heeft er helemaal geen verband bestaan tussen de afstand van de bezittingen aan de kust van Guinea en de totstandkoming van het tractaat voor de werving van Hindostanen voor Suriname. Het misverstand kon ontstaan, doordat drie tractaten (het Siak-tractaat, het wervingstractaat en het Goudkust-tractaat) gelijktijdig door het Parlement werden behandeld en alle drie zelfs op dezelfde dag aan de Eerste Kamer werden aangeboden.

Dit nieuwere inzicht danken wij aan het onderzoek van Mej. Mollema, ${ }^{6}$ die zich heeft bezig gehouden met de beantwoording van de vraag, of de Goudkust aan Engeland werd afgestaan in ruil voor de verkrijging van de vrije hand in Atjeh, zoals altijd beweerd wordt, en die tot de conclusie kwam, dat zulks niet het geval was: hoewel beide tractaten gezamenlijk en gelijktijdig tot stand kwamen, heeft er helemaal geen verband tussen de twee bestaan.

Ofschoon zij zich niet expliciet heeft ingelaten met de beantwoording van de vraag, of de afstand van de Goudkust geschiedde in ruil voor de werving van Hindostanen, kunnen wij uit het in haar betoog verwerkte materiaal duidelijk concluderen, dat er van een compensatie van het ene voor het andere geen sprake kan zijn geweest. 
Bij het schrijven van zijn bijdrage schijnt Merjer niet op de hoogte te zijn geweest van dit artikel, anders zou hij beslist rekening hebben gehouden met wat daarin verwerkt is. Voor een juist begrip van deze kwestie schijnt het niet van belang ontbloot te zijn een en ander wat nader te bezien. Bij onze uiteenzetting zullen wij herhaaldelijk putten uit het verhelderende artikel van Mej. Mollema.*

Het blijft een merkwaardig feit, dat slechts enkele jaren voor de Europese mogendheden een wedloop om het bezit van koloniën in Afrika begonnen, Nederland zich vrijwillig uit het laatste deel van zijn eens zo uitgestrekte Afrikaanse bezittingen terugtrok. Krachtens een tractaat, dat op I7 februari I872 bekrachtigd werd, vond op 6 april 1872 de plechtige overdracht van de Goudkust aan Engeland plaats. In de proclamatie van overdracht stond o.a. "dat de onvoldoende staat van zaken ter Kuste van Guinea sedert vele jaren 's Konings aandacht heeft getrokken. Zijner Majesteits wensch om aldaar vrede en rust te verzekeren, gelijk die elders in de Nederlandsche bezittingen heerschen, bleef onvervuld." ?

Reeds uit deze proclamatie blijkt, dat er moeilijkheden bestonden, die Nederland niet kon overwinnen en die het deden besluiten om het gebied af te staan. Deze moeilijkheden vonden haar oorzaak in de veroveringszucht van Ashanti, welke telkens leidde tot oorlogen met Fanti, en waarbij zowel Nederland als Engeland betrokken raakten. In I 826 werd zelfs het bestaan van de Europese nederzettingen bedreigd, en toen al polste Nederland Engeland over een eventuele overname, terwijl Engeland ook overwoog zich terug te trekken. Engeland's positie werd echter versterkt onder de bekwame gouverneur GEORGE MACLEAN, door het sluiten van een voordelig tractaat met Ashanti in I83I. $\mathrm{Nu}$ brak een tijd van rust en welvaart aan en in I859 deed Engeland een voorstel om de Nederlandse bezittingen voor 50 à 60.000 pond sterling over te nemen. Toen echter in I863 er toch weer een Ashanti-Fanti oorlog uitbrak, raakten de Engelsen in zo'n moeilijk parket, dat ze in 1865 nogmaals overwogen de Goudkust te verlaten.

- Tijdens onze studie werd onze aandacht op dit artikel gevestigd door Prof. Dr. W. PH. CoolhaAs, die wij dan ook voor het hierdoor gewonnen inzicht zeer erkentelijk zijn. Onze dank ook aan de Uitg. Van Gorcum \& Co (Assen) en aan Mej. Mollema voor de verleende toestemming om van het artikel gebruik te maken. 
Intussen was in Nederland reeds meermalen het verlaten van de Goudkust overwogen. Naarmate de kolonie ruimere staatsbijstand behoefde, werd steeds dringender de vraag in de Volksvertegenwoordiging gesteld, of het behoud van deze schadepost voor Nederland wel verantwoord was. In 1863 antwoordde de regering, dat "mogt zich te eeniger tijd de gelegenheid voordoen om van die bezittingen op voordeelige voorwaarden afstand te doen, men de zaak alsdan in overweging zou kunnen nemen". Maar tussen I865 en I868 sprak ze zich tegen afstand uit, waarbij ze echter verzweeg, dat Engeland bij het polsen over deze kwestie zich volstrekt ongenegen tot overname had getoond!

In I868 was DE WAAL Minister van Koloniën geworden, die zich toelegde op krachtige bezuiniging van de koloniale uitgaven, om welke reden hij op 4 december I 868 tot de Minister van Buitenlandse Zaken het verzoek richtte "te willen overwegen de wijze waarop c.q. de loslating der genoemde koloniën (n.l. de koloniën die lastposten voor Nederland waren, in het bijzonder Curaçao en Goudkust) door Zr Ms Gezantschappen zou kunnen worden bevorderd". Echter kwam van de afstand voorlopig niets, omdat Minister Roest van LIMBURG, hoewel geheel instemmend met de zienswijze van zijn ambtgenoot, geen officieuze stappen durfde te doen zonder eerst machtiging van de Koning bekomen te hebben.

Minister DE WAAL legde daarom, in overeenstemming met de Ministerraad, op I7 april I869 * aan de Koning een rapport voor, waarin hij wees op de penibele situatie in Afrika. Volgens hem stond men thans op een keerpunt in de politiek ten aanzien van de Goudkust, en hij stelde de vraag, of het niet "in het wezenlijk belang der betrokken volkeren zou zijn, dat Nederland zich van de Kust van Guinea terugtrok?". De Koning zond dit rapport aan de Raad van State, die op I juni I869 een geheel afwijzend advies uitbracht, zodat deze kwestie voor ongeveer een jaar van de baan was.

Met medeweten van de Minister van Koloniën werden echter door Commissaris NagTgLas "op bedekte wijze informatiën ingewonnen" naar een eventuele bereidheid tot overname bij de Franse en Engelse Goudkust autoriteiten, terwijl de Minister van Buitenlandse Zaken de Engelse gezant in Nederland, ViceAdmiraal HarRIs, van een en ander op de hoogte had gesteld. Maar dit alles werd verzwegen, toen DE WAAL op 2I mei I870

\footnotetext{
- In het artikel van Mej. Mollema staat bij vergissing: 17 april 1870.
} 
aan de Koning schreef: "De Regeering van Groot-Britannië deed (vertrouwelijk) het voorstel de Nederlandsche bezittingen ter Kuste van Guinea over te nemen". Op 2I juni I87o bracht de Raad van State een gunstig advies uit, met aantekening dat niet op financiële basis, doch "slechts in verband met de verzekering van ons gezag en van onzen invloed in Oost-Indië" tot eventuele afstand mocht worden overgegaan.

$\mathrm{Nu}$ konden de onderhandelingen met Engeland worden geopend, waarbij de Nederlandse regering, zonder een officieel voorstel van de Engelsen daartoe af te wachten, zelf er mee begon. Dit "provoceeren" (zoals Minister DE WAAL het noemde) toont duidelijk, hoe hoog de kwestie Nederland zat en hoe snel het ervan bevrijd wilde zijn! Vanaf de aanvang van de onderhandelingen stelde de Engelse regering zich dan ook op het standpunt, dat zij Nederland door het van deze schadepost te ontlasten, een gunst bewees, waarvoor geen compensaties nodig waren! Het is nu al duidelijk, dat de afstand van de Goudkust aan Engeland niet kan worden gezien als een compensatie voor de werving van Hindostanen, noch als een ruil voor de verlening van de vrije hand in Atjeh.

Sedert enige tijd was Nederland namelijk bezig om een herziening te verkrijgen van het Sumatra-tractaat, dat verbood om Engeland van de handel op Sümatra uit tê sliuitên. Nadat in 1858 Siak en onderhorigheden zich onder Nederlands gezag hadden gesteld, waren de betrekkingen met Atjeh slechter geworden, waardoor Nederland dringend het tractaat veranderd wenste. Aan de andere kant hadden de Engelsen ook belang bij de herziening, daar ze het niet konden velen dat het Sumatra-tractaat aan Nederland toestond om de Engelse handelaars in dit gebied invoerrechten tot het dubbele van die voor zijn eigen onderdanen te heffen. Onderhandelingen over deze kwestie werden op I9 september 1868 geopend en leidden tot een ontwerp-tractaat, waarbij Engeland van alle protesten tegen gezagsuitbreiding in Siak afzag in ruil voor de afschaffing van de differentiële rechten.

Intussen hadden onderhandelingen om te komen tot werving van Hindostanen in het toenmalige Brits-Indië om als arbeidskrachten te dienen voor de plantages in Suriname, geleid tot de opstelling van een ander tractaat. De ontwerptractaten voor de werving en voor Siak waren reeds ter tekening gereed, toen de kwestie van de Goudkust op de proppen kwam, zodat bezwaarlijk kan worden volgehouden, dat de afstand van de Goudkust geschiedde in ruil voor het recht om Hindostanen te werven of 
als compensatie voor het verlenen van de vrije hand in Sumatra. En nog duidelijker blijkt dit, wanneer wij het verdere verloop van het Goudkust-tractaat nagaan.

Op II juli I870 stelde de Minister van Buitenlandse Zaken de Engelse gezant officieel de overname van de Goudkust voor, mits aan het wervingstractaat een ruimere toepassing werd gegeven en het Siak-tractaat in die zin werd uitgebreid, dat Nederland ontslagen werd van de belofte inzake de eerbiediging van Atjeh's onafhankelijkheid. In zijn brief van I4 juli I870 deelde Lord Granville, Secretary of State for Foreign Affairs, mede "with considerable surprise" te hebben gelezen, dat de Nederlandse regering aan de afstand van de Goudkust voorwaarden had verbonden, die moesten leiden tot heropening van de onderhandelingen over tractaten, die reeds "by mutual consent" waren geregeld. "To these suggestions I have to reply that Her Majesty's Government are not disposed to enter upon fresh negotiations on these subjects or to reopen those already closed".

Deze mededeling was een koude douche voor Nederland, dat in deze kwestie bijzonder zwak stond, niet alleen omdat er reeds overeenstemming was bereikt inzake het wervings- en het Siaktractaat, maar nog meer omdat Nederland zelf het initiatief tot de afstand van de Goudkust had genomen en het Engelse voorstel tot overname had uitgelokt. Vandaar dan ook, dat Nederland niets anders kon doen dan bakzeil halen, en zonder aan enige verdere concessies te denken op 8 september I870 de ontwerptractaten over Siak en de werving van Hindostanen in hun oorspronkelijke vorm tekende!

De Engelsen hadden echter ook bezwaar tegen het concept betreffende de afstand van de Goudkust, en Nederland kwam hierin aan al hun wensen tegemoet. Engeland verzocht het Siaktractaat en het wervingstractaat bij de behandeling in de StatenGeneraal samen te koppelen: mocht het eerste tractaat niet worden aangenomen, dan zou de werving van Hindostanen evenmin worden toegestaan. Minister DE WAAL - wiens pogingen om Engeland te bewegen de overname te compenseren door een voordelige toepassing van de reeds gesloten tractaten, waren mislukt - zag in dit verzoek een middel om zijn prestige te redden. Hij stelde Engeland als tegenprestatie voor koppeling van het Siak- en het wervingstractaat op zijn beurt een koppeling van deze beide tractaten met het Goudkust-tractaat voor, waardoor niet alleen alle drie tractaten gelijktijdig zouden worden behandeld, maar ook met elkaar zouden staan of vallen. Daar 
Engeland hiertegen geen bezwaar had, werd op 24 oktober I870 HARRIS gemachtigd door Granville om het gewijzigde concept goed te keuren.

Met de verbinding van het lot van de drie tractaten aan elkaar bereikte DE WAAL, dat de indruk kon worden gevestigd, dat de afstand van de Goudkust diende tot compensatie van de Engelse erkenning van de Nederlandse souvereiniteit over Siak en van de toestemming tot werving van Hindostaanse immigranten in het toenmalige Brits-Indië. En tegelijkertijd bereikte hij ermee, dat de Volksvertegenwoordiging verplicht werd om voor de afstand te stemmen, daar ze zich er wel voor zou hoeden om door afstemming van het ene tractaat ook over het lot van de beide andere tractaten te beslissen!

Alles dreigde weer te mislukken, toen de intussen demissionair geworden Minister van Buitenlandse Zaken weigerde te tekenen: ROEST VAN LIMBURG was blijkbaar onder de indruk gekomen van de hevige protesten, die de Nederlandse pers deed horen na het uitlekken van de overdrachtsplannen. De nieuwe Minister van Koloniën, vaN Bosse, vond het ook gewenst om de samenhang tussen de drie tractaten te niet te doen. Maar de nieuwe Minister van Buitenlandse Zaken, Gericke van Herwijnen, achtte zulks niet doenlijk en wilde dat de zaak snel haar beslag zou krijgen. Vooral met het oog op de gespannen toestand aan de Goudkust werd het reeds door DE WAAL opgesteld rapport op I3 februari I87I aan de Koning voorgelegd, die op 23 februari zijn volmacht verleende, zodat op 25 februari $187 \mathrm{I}$ des voormiddags te II uur de Ministers Gericke en van Bosse ter ener en Vice-Admiraal HARRIs ter anderer zijde het ontwerptractaat tekenden, waarbij de Goudkust aan Engeland werd overgedragen tegen een schadeloosstelling voor gebouwen en inventaris voor een nader te bepalen bedrag (maximaal 24.000 pond sterling).*

In zijn advies van 4 april I87I sprak de Raad van State een hoogst afkeurend oordeel uit, zowel over de wijze van onderhandelen (door vooruit te lopen op het officiële Britse voorstel, waardoor de overname een gunst van Engeland werd) als over de strekking en aard van het tractaat zelf, en stelde voor om nogmaals contact met Engeland op te nemen voor de verkrijging van betere compensaties. De Ministers antwoordden, dat geen redelijk argument voor het behoud van de Goudkust kon worden gevonden, en vreesden dat de kans, dat wanneer het

\footnotetext{
* Op I januari r873 ontving Nederland een bedrag van $f$ 46.939,62 aan
} schadeloosstelling plus rente. 
Engelse Parlement eenmaal in deze zaak zou worden gemengd, dit het tractaat zou verwerpen, niet uitgesloten moest worden geacht. De Ministers verzwegen echter, dat tengevolge van de gebeurtenissen aan de Goudkust, de Engelsen de laatste maanden een voortdurend groter wordende tegenzin tot overname aan de dag legden!

Daar de Nederlandse regering het risico van een heropening van de onderhandelingen niet aandurfde, werd het advies van de Raad van State niet opgevolgd. Op 23 april I87I werden bij Koninklijke Boodschap de gedeelten der tractaten, die de goedkeuring der Staten-Generaal behoefden, aan de Tweede Kamer aangeboden. Hier werd de regering fel aangevallen en er vielen zelfs uitdrukkingen als "een brevet van onmacht", "schande voor de nationale eer" en "een vlek op de Nederlandsche vlag". Beide Ministers meenden evenwel, gezien de moeilijke stand van zaken aan de Goudkust, de afstand nadrukkelijk te moeten aanbevelen. Tenslotte werd het tractaat van afstand op 2 juli $187 \mathrm{I}$ met 34 tegen 30 stemmen toch aangenomen, maar tegen de verwachting in werd het Siak-tractaat met 36 tegen 38 stemmen verworpen!

Aangezien de tractaten connex waren, zou nu ook het Goudkust-tractaat moeten worden teruggenomen (evenals het wervingstractaat). Daarom wendde de regering zich weer tot Engeland, dat tot hervatting van de onderhandelingen bereid bleek. Op I6 oktober I87I werd overeenstemming bereikt, waarbij Engeland de vrije hand in Atjeh aan Nederland toestond. Wat Minister DE WAAL dus met de overdracht van de Goudkust niet had kunnen bereiken, stond Engeland nu toe, omdat de differentiële rechten op het spel stonden!

$\mathrm{Na}$ deze nieuwe ontwikkeling verliepen de behandeling van het Atjeh-tractaat en de herbehandeling van het wervingstractaat in de Tweede Kamer bijzonder vlot, ofschoon verscheidene leden de vraag stelden, waarom ook het Goudkust-tractaat niet weer aan het oordeel van de Kamer werd onderworpen. Alle drie tractaten werden op dezelfde dag aangeboden aan de Eerste Kamer, die de regering haar critiek ook niet spaarde; zo werd er opgemerkt: "voor de afstand bestaat eigenlijk geen ander motief dan de geldkwestie en deze beweegreden kan bezwaarlijk als eervol worden aangemerkt". Toch werd het Goudkust-tractaat op I7 januari I 872 met 29 tegen 6 stemmen aanvaard.

Uit het voorgaande is duidelijk gebleken, dat hoewel de drie tractaten gezamenlijk en gelijktijdig tot stand kwamen, en hoe- 
wel Minister DE WAAL zijn uiterste best heeft gedaan om te compenseren, er van een afstand van de Goudkust in ruil voor het recht om Hindostanen te werven of voor het verkrijgen van de vrije hand in Atjeh helemaal geen sprake is geweest. Toch is er verband gelegd zowel door tijdgenoten als door het nageslacht. Zoals uit de door ons aan het begin geciteerde recente literatuur blijkt, beschouwt men nog steeds de afstand van de Goudkust als een compensatie voor de immigratie van Hindostanen. En Mej. Mollema schrijft, dat men in de afstand der Goudkust nog steeds een compensatie ziet voor het verkrijgen van de vrije hand in Atjeh. Wij kunnen volkomen met haar instemmen, wanneer ze zegt, dat zulks wellicht een onbewuste poging is om de bittere pil van nationale onmacht te vergulden.

\section{AANTEKENINGEN}

I. Wet van 20 januari 1872 . Stbl. No. 4.; K.B. van 22 maart 1872 No. 27 ; Publicatie van 3 mei 1872 (G.B. No. 8). - Het tractaat van 8 september 1870 is gepubliceerd in Speciale Wetgeving op de Immigratie en Kolonisatie van Suriname. Leiden, zonder jaartal, p. 15-36.

2. Immigratie-Rapport. Bijlage III p. xvi. (genoemd in DE KLERK)

3. C. J. M. DE KLERK: De Immigratie der Hindostanen in Suriname. Amsterdam 1952; P: 40, n: 22:

4. G. J. KruIJER: Suriname en zijn Burrlanden. Lichtplekken in het Oerwoud van Guyana. Meppel 1953, p. 72.

5. J. MEIJER: Suriname en de Nederlandse Antillen. 1795-I945. In: Algemene Geschiedenis der Nederlanden. Deel XII. Zeist 1958, p. 286.

6. A. M. P. Mollema: De Afstand der Nederlandse Bezittingen ter Kuste van Guinea aan Engeland in 1872. In: Varia Historica. Assen 1954, p. $215^{-242}$.

7. Nederlandsche Staatscourant April 1872. (genoemd in Mollema)

\section{SUMMARY}

THE IMMIGRATION OF HINDUSTANIS AND

THE CESSION OF THE GOLD COAST

It is generally held, both in the older and in the recent literature on Surinam, that the treaty between the Netherlands and England in 1870 , under which the immigration of Hindustanis in Surinam became possible, was concluded as a compensation for the cession of the Dutch possession of the Gold Coast to England.

The author, drawing from recent historical research, falsifies this contention and shows that there cannot have been any connection between these two treaties, because the treaty for recruitment of labourers in 
British India was ready for signing, when the subject of the Gold Coast was broached.

The present article deals in a rather detailed manner with the activities concerning the conclusion of these treaties, especially of the Gold Coast treaty. From this discussion it becomes clear that, although the Minister of Colonies, DE WAAL, did his utmost best to compensate, there cannot be any talk of a barter in this matter.

The misunderstanding could arise because three treaties (the recruitment treaty, the Gold Coast treaty and the Siak treaty) were simultaneously considered by the Dutch Parliament; as a matter of fact, the three treaties were presented to the First Chamber on the same day. With this manipulation DE WAAL succeeded in creating the wrong impression of compensation. 